\title{
COUMARIN (ESCULETIN) - AN ANTIRHEUMATOID ARTHRITIC COMPOUND: AN UPDATE
}

\author{
JAYA KUMARI S*, ANANDHI N, MOUNISHA B, MOHAMED SAMEER MH
}

Department of Pharmacognosy, School of Pharmaceutical Sciences, Vels Institute of Science Technology and Advanced Studies, Pallavaram, Chennai, Tamil Nadu, India. Email: nisajayaa@gmail.com

Received: 11 October 2018, Revised and Accepted: 15 December 2018

\section{ABSTRACT}

Context: Esculetin is a natural polyphenolic compound. It is chemically 6,7-dihydroxycoumarin and one of the ingredients of Cortex fraxini, a Chinese traditional medicine. It is used as a dietary supplement and found as non-toxic. Recently, there are many research works evaluated on esculetin in arthritis with supported molecular mechanisms.

Objectives: Esculetin becoming more attractive prodrug for arthritis. Hence, the present minireview will consolidate the targeted site of esculetin in the treatment of arthritis over the past decade.

Results: The most important molecular mechanism of esculetin is an antioxidant activities with decreased level of reactive oxygen species/reactive nitrogen species. It also inhibited lipoxygenase 5, lipoxygenase 12 , and tyrosinase enzymes. It reduces the inflammation by modulating the key inflammatory enzyme matrix metalloproteinase-1 activity. It also lowers the nitrous oxide and prostaglandin E2 level in synovial fluid. Esculetin derivatives such as 5-methoxy esculetin inhibited the activity of nitrogen-activated protein kinases. The updated data also reveal that esculetin suppresses the leukotriene B4 level in plasma of adjuvant-induced arthritis tested animals.

Conclusion: The presented update showed that esculetin may be useful as a tool in regulating the mechanism and physiological functions of the inflammatory mediators and enzyme. Hence, the presented review work may be considered as a scientific proof for the development of an attractive drug candidate for the patient with rheumatoid arthritis.

Keywords: Coumarin, Esculetin, Rheumatoid arthritis, Molecular mechanism.

(C) 2018 The Authors. Published by Innovare Academic Sciences Pvt Ltd. This is an open access article under the CC BY license (http://creativecommons. org/licenses/by/4. 0/) DOI: http://dx.doi.org/10.22159/ajpcr.2018.v11s4.31710

\section{INTRODUCTION}

Rheumatoid arthritis (RA) is an autoimmune inflammatory disease. It influences around $1 \%$ of population. Around $80 \%$ of affected patients are disabled after 20 years. Economically accessible conventional medications are moderate acting and are having restricted adequacy and lead to many unwanted symptoms. Moreover, they do not enhance the long-term treatment of RA. Esculetin, 6,7-dihydroxycoumarin, is a coumarin subordinate found in different plants, Cortex fraxini is one of the generally utilized conventional Chinese prescriptions [1]. It has been shown that Cortex fraxini has different pharmacological impacts, including hostile to pathogenic [2], calming [3], analgesic [4], against malignant growth [5], antioxidative activity [6], neuroprotective [7], and vascular defensive impacts [8]. It is one of the fundamental dynamic elements of Cortex fraxini, has been used as expectorant, against tussive [9] cell reinforcement, hostile to bacterial, and hostile to tumor [10]. Particularly, esculetin, asculin, fraxin, and fraxetin are found in Cortex fraxini explored as major pharmaceutical active ingredients [11]. Esculetin is becoming more attractive prodrug for arthritis. Recently, there are many research works evaluated on esculetin in arthritis with supported molecular mechanisms. Hence, the present minireview will focused to consolidate the targeted site of esculetin in the treatment of arthritis over the past decade.

\section{PROFILE OF THE COMPOUND ESCULETIN}

Esculetin is aglycone of esculin, a coumarin glycoside naturally occurs in horse chestnut:

- Aesculus hippocastanum.

- Aesculus california.

Family: Sapindaceae
The term esculetin - derived from the genus name, Aesculus.

\section{Properties of esculetin}

- Molecular formula: $\mathrm{C}_{9} \mathrm{H}_{6} \mathrm{O}_{4}$

- Molecular weight: $178.14 \mathrm{~g} / \mathrm{mole}$

- Physical state: Pale yellow amorphous powder

- Melting point: $265-270^{\circ} \mathrm{C}$

- Solubility: Sparingly soluble in water. Readily soluble in methyl alcohol

- $\quad$ H: Weakly acid.

\section{Chemistry of esculetin}

IUPAC name: 6,7-Dihydroxy-2H-chromen-2-one

6,7-dihydroxy-2-benzopyrone.

\section{Chemical test}

Ethanolic solution of the sample is treated with $0.5 \mathrm{ml}$ of $10 \%$ ammonium hydroxide solution and examined under UV light. Intense fluorescence is observed esculetin form dark brown or black color complex with ferric salt.

\section{Pharmacological properties}

Anti-inflammatory effect

Esculetin decreases the production of NO to manage blood vessels and facilitates the organ tissue destruction swelling; then again, esculetin inhibits the production of soluble intercellular adhesion molecule (sICAM-1), which can decrease the adhesion reaction of leukocytes and endothelial cells in sequence to decrease inflammation [12]. Esculetin was found to secure myocardial from ischemia-reperfusion damage [13]. 
Table 1: A study report of esculetin on anti-inflammatory potential in arthritis

\begin{tabular}{|c|c|}
\hline S. No. & Work done \\
\hline 1. & $\begin{array}{l}\text { Studied effect the newly synthesized mitochondria-targeted } \\
\text { esculetin for its antiatherosclerotic potential [23] }\end{array}$ \\
\hline 2. & $\begin{array}{l}\text { Studied the cell - biotransformation glycoside } \\
\text { derivatives (esculetin its 6-glycoside esculetin) using } \\
\text { engineered E. coli and Neisseria polysaccharide } \\
\text { amylosurase [24] }\end{array}$ \\
\hline 3. & $\begin{array}{l}\text { Reported the antiadipogenic activity of esculetin. Through } \\
\text { the modulation of antioxidant enzymes [25] }\end{array}$ \\
\hline 4. & $\begin{array}{l}\text { Assessed pharmacological exercises and compound of } \\
\text { esculetin and its derivatives [26] }\end{array}$ \\
\hline 5. & $\begin{array}{l}\text { The results of their findings shown that the esculetin } \\
\text { displayed stimulant-like impact which may be identified } \\
\text { with the restraint of NF-KB pathway and the enactment of } \\
\text { BNF/Trkb signaling [11] }\end{array}$ \\
\hline 6. & $\begin{array}{l}\text { Revealed the potential effectiveness of esculetin in the } \\
\text { treatment of mental issue with aggravation and oxidative } \\
\text { pressure [27] }\end{array}$ \\
\hline 7. & $\begin{array}{l}\text { Reported (for the } 1^{\text {st }} \text { time) the 5-methoxy esculetin } \\
\text { inhibited lipopolysaccharide instigated aggravation } \\
\text { by smothering MAPK and AP-1 pathway in RAW } 264.7 \\
\text { cells [28] }\end{array}$ \\
\hline 8. & $\begin{array}{l}\text { Review work was done on compound, natural exercises, } \\
\text { and medicinal properties of esculetin and its derivative [29] }\end{array}$ \\
\hline 9. & $\begin{array}{l}\text { Investigated defensive impact esculetin in LPS make } \\
\text { long aggravation might be credit halfway to the restraint } \\
\text { of NF-KB and RhoA/Rho kinase pathway in vivo and } \\
\text { in vitro [30] }\end{array}$ \\
\hline 10. & $\begin{array}{l}\text { Studied and found out the inhibitory effect of esculetin on } \\
\text { the coupling exercise of NF-KB and AP-1 in TNF-alpha treat } \\
\text { vascular smooth muscle cells [31] }\end{array}$ \\
\hline 11. & $\begin{array}{l}\text { Isolated coumarin and (herniarin esculetin, scopolin, } \\
\text { and scopoletin) from Santolina oblongifolia and } \\
\text { studied inhibitory action of eicosanoid release from } \\
\text { ionophore-stimulated mouse peritoneal macrophages [32] }\end{array}$ \\
\hline 12. & $\begin{array}{l}\text { Studied anti-inflammatory action of benzopyrones by } \\
\text { inhibition of cyclo- and lipo-oxygenase using croton oil ear } \\
\text { test in mice [33] }\end{array}$ \\
\hline 13. & $\begin{array}{l}\text { Studied anti-inflammatory and peripheral analgesic activity } \\
\text { of esculetin in animal model [34] }\end{array}$ \\
\hline 14. & $\begin{array}{l}\text { Decrease the attachment response of leukocytes and } \\
\text { additionally endothelial cells keeping in mind the end goal } \\
\text { to decrease inflammation [35] }\end{array}$ \\
\hline 15. & $\begin{array}{l}\text { Diminished the statement of framework MMP-1 } \\
\text { (reduce inflammation) [12] }\end{array}$ \\
\hline 16. & $\begin{array}{l}\text { Lowered the nitrous oxide (decrease tissue damage from } \\
\text { inflammation) and PGE2 level in synovial liquid [36] }\end{array}$ \\
\hline 17. & $\begin{array}{l}\text { Protected myocardial from ischemia-reperfusion by } \\
\text { systemic inflammation [13] }\end{array}$ \\
\hline 18. & $\begin{array}{l}\text { Studied antioxidant activities with decreased level of ROS/ } \\
\text { RNS (reduced DNA damage), inhibited the lipoxygenase and } \\
\text { tyrosinase enzymes [37] }\end{array}$ \\
\hline
\end{tabular}

PGE2: Prostaglandin E2, MMP-1: Metalloproteinase-1, MAPK: Nitrogen-activated protein kinase, ROS/RNS: Reactive oxygen species/reactive nitrogen species, NF-KB: Nuclear factor-kappa B, AP-1: Activate or protein-1, BNF: Brain-derived neurotrophic factor, Trkb: Tropomyosin-related kinase receptor B, TNF: Tumor necrosis factor, E. coli: Escherichia coli

\section{Antitumor effects}

Esculetin is a phenolic composite that is found in regular plant items and produces apoptosis in various kinds of human malignant growth cells. Esculetin has been appeared to specifically produce tumor apoptosis in various types of malignant growths and is considered as a promising chemotherapeutic agent. Acute promyelocytic leukemia is a kind of disease, in which undevelopment cells called promyelocytes multiply uncommon. Esculetin is found to restrain the survival of human promyelocytic leukemia cells in a fixation ward and time-subordinate way $[14,15]$.

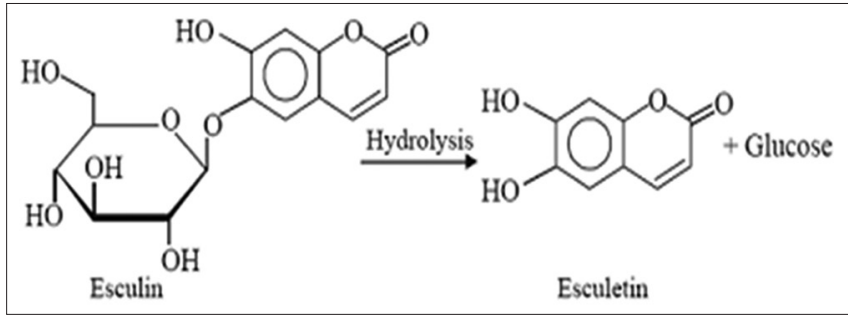

Fig. 1:

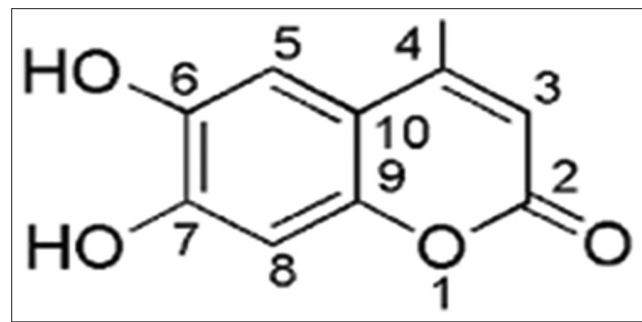

Fig. 2: Chemical structure of esculetin

\section{Hepatoprotective effects}

Esculetin is found to have against hepatotoxic movement and the manifestation of this compound in Cichorium intybus and Bougainvillea spectabilis may clarify the folkloric utilization of these plants in liver damage [16].

\section{Antidiabetic effects}

It was established on the research of Prabakaran, esculetin is the treatment and prevention of diabetes mellitus. It can reduce hyperglycemia-mediated oxidative stress by antioxidant competence in both hepatic and renal tissue [17].

\section{Antibacterial effects}

The human pathogen Escherichia coli are spread by direct or indirect contact with cause disease in animal and human stools. E. coli is the most widely recognized reason for hemorrhagic colitis. The expansion of esculetin to human fecal slurries and in vitro non-stop stream fermenter models reproducing conditions in the human colon and rumen caused checked reductions in the survival of a presented strain of E. coli [18].

\section{Antioxidant effects}

Esculetin is likewise an intense specialist in cells from reactive oxygen species (ROS)-mediated abeta destruction [19]. In another examination, esculetin is successful securing cells against DNA injury incited by oxidative pressure [16].

\section{Inhibits of the proliferative of vascular smooth muscle cell (VSMC)} The multiplication of VSMCs incited by damage to the intima of supply routes is an essential pathogenic factor in vascular proliferative disarranges including atherosclerosis and restenosis. Esculetin can effectively interfere with the multiplication of rVSMCs in vitro in a portion and time-subordinate way [20].

\section{Suppression of Adipogenesis}

Esculetin has the impact of advancing glucose digestion and intervenes adipocyte apoptosis by the mitochondrial pathway starting the apoptotic procedure of 3T3-L1 adipocytes [21]. Another trial showed that esculetin has hostile to adipogenic impacts through adjustment of peroxisome proliferator-activated receptor $\gamma$ and CCAAT/enhancer binding protein $\alpha$ by means of the AMP-activated protein kinase flagging pathway [22]. 
Flow diagram for pathogenesis of arthritis

- During sepsis - lipopolysaccharide (a bacterial endotoxin) released from bacteria trigger the macrophages for the production of tumor necrosis factor alpha (TNF $\alpha$ ), subsequently interleukin (IL)-1 and IL-6.

- Both TNF $\alpha$ and IL can stimulate the production of collagenase and PGE 2 by synovial cells to cause joint damage in arthritis.

- In patient with RA, the synovial membrane is characterized by increased vascularity, infiltration of inflammatory cells, primarily CD4+T cells.

- The antigen-activated CD4+T cells stimulate monocytes/ macrophages to produce the cytokines IL-1, IL-6, and TNF $\alpha$.

- These are the key cytokines and hallmark of inflammation in RA.

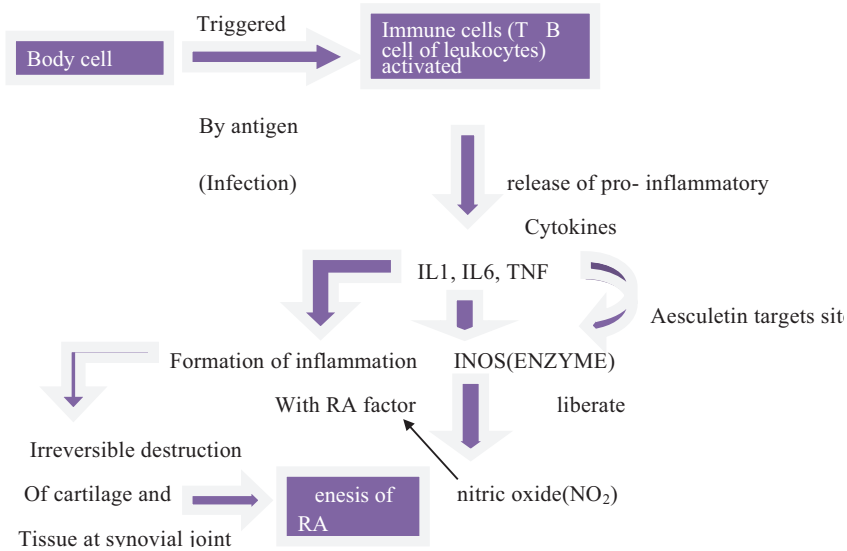

\section{DISCUSSION}

RA is a common autoimmune inflammatory disease. $80 \%$ of affected are disabled after 20 years. Rheumatoid joint pain is characterized by expanded vascular invade of fiery cells - CD $4 \alpha \mathrm{T}$ cells, which invigorate plasma cells to deliver proinflammatory cytokines IL-1, IL-6, and TNF. There are many research works around at the UN Food and Drug Administration approved drugs for RA the trend today, especially in all industrial settings are to seek the bioactive marker that will serve as compound for synthetic and semi-synthetic drug development to RA. In this concert, the present work an update was done on natural coumarin esculetin - a biomarker for the available scientific data in the management of inflammatory problem in RA. The most important molecular mechanism of esculetin is an antioxidant activity with decreased level of reactive oxygen species/ reactive nitrogen species (ROS/RNS). It also inhibited lipoxygenase 5, lipoxygenase 12, and tyrosinase enzymes. It reduces the inflammation by modulating the key inflammatory enzyme matrix metalloproteinase-1 activity. It also lowers the nitrous oxide and prostaglandin E2 level in synovial fluid. Esculetin derivatives such as 5-methoxy esculetin inhibited the activity of nitrogen-activated protein kinases. The updated data also reveal that esculetin suppresses the leukotriene B4 level in plasma of adjuvant-induced arthritis tested animals.

\section{CONCLUSION}

The presented review data revealed that the selected compound was investigated for different inflammatory activities in arthritis. Among the updated review of the biological effects and molecular mechanisms of esculetin, cell reinforcement action assumes an essential part connected with diminished levels of ROS/RNS, which is further conceivably identified with the counter proliferative, calming, against phospholipids disorder, and other pharmacological activities. The presented update showed that esculetin may be useful as a tool in regulating the mechanism and physiological functions of the inflammatory mediators and enzyme. Hence, the presented review work may be considered as a scientific proof for the development of an attractive drug candidate for the patient with RA.

\section{REFERENCES}

1. Yang TM, Ge X, Wang XN. Med J Natl Defending Forces Northwest China 2003;24:387.

2. Weng YC, Liu JW, Cui C, Zhao QC. Isolation and identification of the constituents from fraxini cortex and their in vitro antibacterial activity. Chin J Med Chem 2014;1:40-7.

3. Liu SQ, He L, Peng H, Liu J. Effect of ash bark on matrix metalloproteinase 1, nitricoxide and prostaglandin E2 in rabbits with experimental osteoarthritis. Chin J Clin Rehabil 2005;9:150-3.

4. Przemyslaw R, Emilia G, Slawomir M, Bujalskazadrozny M. Antinociceptive properties of esculetin in non-inflammatory and inflammatory models of pain in rats. Clin Exp Pharmacol Physiol 2015;42:213-9.

5. Kaneko T, Tahara S, Takabayashi F. Inhibitory effect of natural coumarin compounds, esculetin and esculin, on oxidative DNA damage and formation of aberrant crypt foci and tumors induced by 1,2-dimethylhydrazine in rat colons. Biol Pharm Bull 2007;30:2052-7.

6. Marinova EM, Yanishlieva NV, Kostova IN. Antioxidative action of the ethanolic extract and some hydroxycoumarins of Fraxinus ornus bark. Food Chem 1994;51:125-32.

7. Zhao DL, Zou LB, Lin S, Shi JG, Zhu HB. Anti-apoptotic effect of esculin on dopamine-induced cytotoxicity in the human neuroblastoma SH-SY5Y cell line. Neuropharmacology 2007;53:724-32.

8. Shabanov PD, Vislobokov AI. Neuronoprotective action of cortexin andcortagen. Rev Clin Pharmacol Drug Ther 2013;11:17.

9. Pan YM. Antioxidant activity of ethanolic extract of cortex fraxini and use in peanut oil. Food Chem 2007;103:913-8.

10. Issa YM, El-Hawary WF, Moustafa ME, Refaat M. ChemInform abstract: Spectroscopic studies on some new azo dyes derived from 4-methylesculetin and their biological activity. J Indian Chem Soc 1997;74:777-80

11. Liang C, Ju W, Pei S, Tang Y, Xiao Y. Pharmacological activities and synthesis of esculetin and its derivatives: A mini-review. Molecules 2017;22:E387.

12. Duan HQ, Zhang YD, Fan K, Suo ZW, Hu G, Mu X. Anti-inflammatory mechanism of esculetin. Chin J Vet Med 2007;43:45-6.

13. Wang ZQ, Xia Y. Protective effect of esculetin on acute myocardial ischemia reperfusion injury in rats. J Chengdu Med Coll 2011;6:49-51.

14. Rubio V, Calviño E, García-Pérez A, Herráez A, Diez JC. Human acute promyelocytic leukemia NB4 cells are sensitive to esculetin through induction of an apoptotic mechanism. Chem Biol Interact 2014;220:129-39.

15. Chu CY, Tsai YY, Wang CJ, Lin WL, Tseng TH. Induction of apoptosis by esculetin in human leukemia cells. Eur J Pharmacol 2001;416:25-32.

16. Gilani AH, Janbaz KH, Shah BH. Esculetin prevents liver damage induced by paracetamol and CCL4. Pharmacol Res 1998;37:31-5.

17. Prabakaran D, Ashokkumar N. Protective effect of esculetin on hyperglycemia-mediated oxidative damage in the hepatic and renal tissues of experimental diabetic rats. Biochimie 2013;95:366-73.

18. Duncan SH, Leitch EC, Stanley KN, Richardson AJ, Laven RA, Flint HJ, et al. Effects of esculin and esculetin on the survival of Escherichia coli O157 in human faecal slurries, continuousflow simulations of the rumen and colon and in calves. Br J Nutr 2004;91:749-55

19. Liang M. Isolation and activity of antioxidant ingredients in cortex fraxini. Sci Technol Food Ind 2006;27:64-6.

20. Dai R, Zheng QL, XU QS, Zhu W. Acta Med Univ Sci Technol Huazhong 2009;38:239-42.

21. Yang JY, Della-Fera MA, Baile CA. Esculetin induces mitochondriamediated apoptosis in 3T3-L1 adipocytes. Apoptosis 2006;11:1371-8.

22. Kim Y, Lee J. Esculetin, a coumarin derivative, suppresses adipogenesis through modulation of the AMPK pathway in 3T3-L1 adipocytes. J Funct Foods 2015;12:509-15.

23. Kim Y, Park Y, Namkoong S, Lee J. Esculetin inhibits the inflammatory response by inducing heme oxygenase- 1 in cocultured macrophages and adipocytes. Food Funct 2014;5:2371-7.

24. Katta S, Karnewar S, Panuganti D, Jerald MK, Sastry BK, Kotamraju S, et al. Mitochondria-targeted esculetin inhibits PAI-1 levels by modulating STAT3 activation and miR-19b via SIRT3: Role in acute coronary artery syndrome. J Cell Physiol 2018;233:214-25.

25. Park S, Moon K, Park CS, Jung DH, Cha J. Synthesis of aesculetin and aesculin glycosides using engineered Escherichia coli expressing Neisseria polysaccharea amylosucrase. J Microbiol Biotechnol 
2018;28:566-70.

26. Kim Y, Lee J. Esculetin inhibits adipogenesis and increases antioxidant activity during adipocyte differentiation in 3T3-L1 cells. Prev Nutr Food Sci 2017;22:118-23.

27. Zhu L, Nang C, Luo F, Pan H, Zhang K, Liu J, et al. Esculetin attenuates lipopolysaccharide (LPS)-induced neuroinflammatory processes and depressive-like behavior in mice. Physiol Behav 2016;163:184-92.

28. Sulakhiya K, Keshavlal GP, Bezbaruah BB, Dwivedi S, Gurjar SS, Munde N, et al. Lipopolysaccharide induced anxiety- and depressivelike behaviour in mice are prevented by chronic pre-treatment of esculetin. Neurosci Lett 2016;611:106-11.

29. Maoa G, Zhanga S, Songa H, Dinga S, Zhua P, Wangb X, et al. Synthesis, biological activities and therapeutic properties of esculetin and its derivatives. J Chem Pharm Res 2015;7:122-30.

30. Wu L, Li X, Wu H, Long W, Jiang X, Shen T, et al. 5-methoxyl aesculetin abrogates lipopolysaccharide-induced inflammation by suppressing MAPK and AP-1 pathways in RAW 264.7 cells. Int J Mol Sci 2016;17:315.

31. Chen T, Guo Q, Wang H, Zhang H, Wang C, Zhang P, et al. Effects of esculetin on lipopolysaccharide (LPS)-induced acute lung injury via regulation of rhoA/Rho kinase/NF-кB pathways in vivo and in vitro. Free Radic Res 2015;49:1459-68.

32. Lee SJ, Lee US, Kim WJ, Moon SK. Inhibitory effect of esculetin on migration, invasion and matrix metalloproteinase-9 expression in TNF$\alpha$-induced vascular smooth muscle cells. Mol Med Rep 2011;4:337-41.

33. Silván AM, Abad MJ, Bermejo P, Sollhuber M, Villar A. Antiinflammatory activity of coumarins from Santolina oblongifolia. J Nat Prod 1996;59:1183-5.

34. Loggix RP. Studied anti-inflammatory action of bazopyrones by inhibition of cyclo and lipo oxygenase using croton oil ear test in mice. 1988.

35. Tubaro A, Del Negro P, Ragazzi E, Zampiron S, Della Loggia R. Antiinflammatory and peripheral analgesic activity of esculetin in vivo. Pharmacol Res Commun 1988;20 Suppl 5:83-5.

36. Liu SQ, He L, Peng H. Effect of esculetin on osteoarthritis in rabbit. Med J Wuhan Univ 2004;9:567-70.

37. Lin HC, Tsai SH, Chen CS, Chang YC, Lee CM, Lai ZY, et al. Structure-activity relationship of coumarin derivatives on xanthine oxidase-inhibiting and free radical-scavenging activities. Biochem Pharmacol 2008;75:1416-25. 